\title{
Metal-Doped Copper Indium Disulfide Heterostructure: Environment-Friendly Hole-Transporting Material toward Photovoltaic Application in Organic-Inorganic Perovskite Solar Cell ${ }^{+}$
}

\author{
Kobra Valadi and Ali Maleki * \\ Catalysts and Organic Synthesis Research Laboratory, Department of Chemistry, Iran University of Science \\ and Technology, Tehran 16846-13114, Iran; valadi43@gmail.com \\ * Correspondence: maleki@iust.ac.ir; Tel.: +98-21-73228313; Fax: +98-21-73021584 \\ + Presented at the 23rd International Electronic Conference on Synthetic Organic Chemistry, \\ 15 November-15 December 2019; Available online: https://ecsoc-23.sciforum.net/. \\ Published: 14 November 2019
}

\begin{abstract}
In this plan, we use Praseodymium metal-doped copper indium disulfide (Pr-doped CIS) heterostructure as hole-transporting materials (HTMs) in the FTO/TiO2/Perovskite absorber/HTM/ $\mathrm{Au}$ device. And photovoltaic performance of these Pr-doped CIS heterostructure was investigated in the fabrication of the organic-inorganic perovskite solar cells (organic-inorganic PSCs).
\end{abstract}

Keywords: green electricity; Pr-coated CuInS2 heterostructure; perovskite solar cells; holetransporting material; solar energy

\section{Introduction}

Recently, by increasing global warming, reducing fossil fuels and increasing greenhouse gas emissions, the generation of green energy through the development of renewable energy sources to provide the human energy needed is excellent importance [1-3]. Generally, among the various sources of renewable energy, such as solar, wind, natural gas and geothermal, solar energy is the most unique source of green energy in the future due to its abundance, ubiquity, unlimited, ecofriendly, low-cost fabrication, clean and easy access [4].

In organic-inorganic PSCs, the $\mathrm{CH}_{3} \mathrm{NH}_{3} \mathrm{PbI}_{3}$ active layer is sandwiched between the electrontransport layer (ETL) and hole-transporting layer (HTL). The common HTL and in order to are spiro MeOTAD and $\mathrm{TiO}_{2}$, in sequence, were used. As well as the ETL and HTL systems and play considerable roles in photovoltaic parameters of the PSCs [5].

However, the replacement and or removal of hole-transporting materials (HTMs) in order to improve the system stability and decrease device cost is beneficial [6].

On the other hand, hybrid nanocomposites are defined as heterogeneous systems with organic and inorganic components that have at least one of its components smaller than 100 nanometers. These hybrid materials not only create a new compound but also improve their properties and applications in various fields [7-25].

For these reasons, we present a novel strategy for the organic-inorganic PSCs bested on the Prdoped CuInS 2 heterostructure as HTM to improve the device photovoltaic performance and energy diagram of the organic-inorganic PSC system as shown in Scheme 1. 


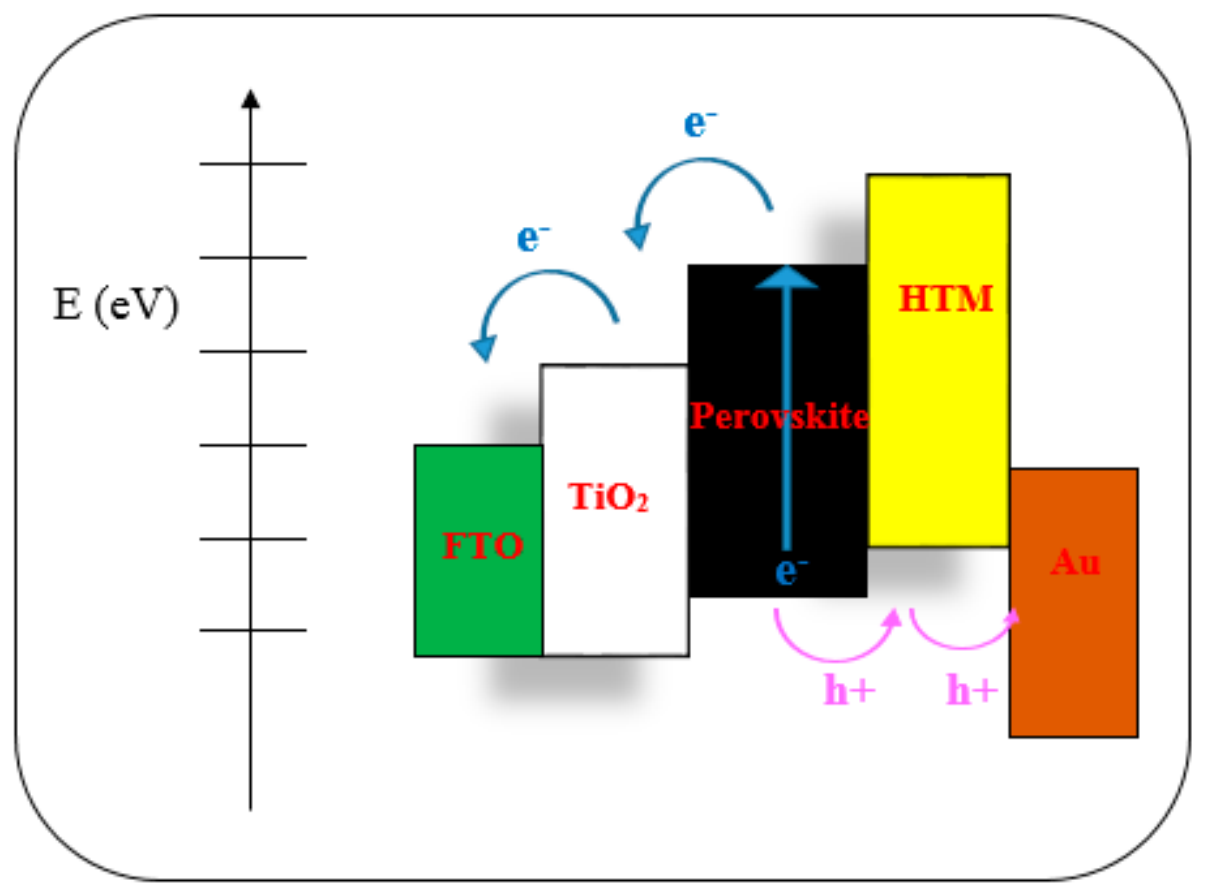

Scheme 1. Energy diagram of different layers used in the organic-inorganic PSC system.

\section{Experimental}

\subsection{General}

All the precursor chemicals were obtained from Alfa Aesar and TCL Chemicals.

\subsection{Synthesis of Pr-doped CuInS 2 Heterostructure}

At first, in a $250 \mathrm{~mL}$ three-neck flask, $0.01 \mathrm{mmol}$ of $\mathrm{CuCl}, 0.01 \mathrm{mmol}$ of $\mathrm{InCl}_{3}, 2 \mathrm{mmol}$ sulfur, 2 $\mathrm{mL}$ of OLA surfactant and the solution containing Pr was added to the reaction system to synthesis of Pr-doped CuInS 2 by using an oil bath at $110^{\circ} \mathrm{C}$ for 30 min under $\mathrm{N}_{2}$ gas were combined. Next, the formation of a black solution, about $2 \mathrm{~h}$ remains at $210{ }^{\circ} \mathrm{C}$ temperature. The product mixture was cooled down to ambient temperature. Then, the product was washed three times with cyclohexane. Second, $1 \mathrm{~mL}$ of cyclohexane, $1 \mathrm{~mL}$ of formamide and $10 \mathrm{mg} \mathrm{Na} 2 \mathrm{~S} \cdot 9 \mathrm{H}_{2} \mathrm{O}$ were mixed and injected into the flask quickly, and the mixture reaction was vigorously by stirred for $10 \mathrm{~min}$. The black solution was centrifuged $\left(12,000 \mathrm{rpm}, 15\right.$ min for per step) and washed several times with EtOH and $\mathrm{H}_{2} \mathrm{O}$. Then, dried in a vacuum oven at $60^{\circ} \mathrm{C}$ overnight.

\subsection{Device Fabrication of PSCS}

F-doped tin oxide (FTO) glasses were washed with distilled water, acetone and ethanol in the ultrasonic bath (10 min for per step), and it was dried under $\mathrm{N}_{2}$ gas. Then, to deposition of $\mathrm{TiO}_{2}$ compact layer, a titanium (IV) isopropoxide (TTIP) solution at $2000 \mathrm{rpm}$ for $30 \mathrm{~s}$ was spin-coated onto the FTO substrate and then dried $500{ }^{\circ} \mathrm{C}$. After that, to loaded $\mathrm{TiO}_{2}$ mesoporous layer, $\mathrm{TiO}_{2}$ paste dissolved in $\mathrm{EtOH}$ and was spin-coated on the upper $\mathrm{TiO}_{2}$ compact layer.

Perovskite absorber layer was loaded via double step spin-coating method on the electron transporting layer; to deposition of lead iodide layer, a $1 \mathrm{M}$ of $\mathrm{PbI}_{2}$ solution was synthesized by added $462 \mathrm{mg}$ lead iodide powder in DMF aprotic solvent at $80{ }^{\circ} \mathrm{C}$, After than $20 \mu \mathrm{L}$ of prepared solution was spin coating on the nanostructure substrate for $3000 \mathrm{rpm}$ at $10 \mathrm{~s} .200 \mu \mathrm{L}$ of MAI solution (35 mg MAI precursor in $5 \mathrm{~mL}$ isopropanol) was loaded by $2000 \mathrm{rpm}$ for $10 \mathrm{~s}$ and was heated at 100 ${ }^{\circ} \mathrm{C}$ for 30 min to form $\mathrm{CH}_{3} \mathrm{NH}_{3} \mathrm{PbI}_{3}$ absorber compound. The Pr-coated $\mathrm{CuInS}_{2}$ suspension as a HTMs layer was loaded at $4000 \mathrm{rpm}$ for $30 \mathrm{~s}$ on the top surface of the $\mathrm{FTO} / \mathrm{TiO}_{2}$ compact/ $/ \mathrm{TiO}_{2}$ 
mesoporous/Perovskite absorber system. Finally, a gold layer was coated via thermal evaporation in the perovskite surface.

\section{Results and Discussion}

To study, the photoelectric performance of the $\mathrm{FTO} / \mathrm{TiO}_{2} /$ perovskite/HTM/Au organic-inorganic PSC based on Pr-doped CIS sample as HTM was tested by current intensity-voltage (J-V) curve and reported under the AM $1.5 \mathrm{G}, 100 \mathrm{mWcm}^{-2}$ illumination (Figure 1). For this systems, the open-circuit voltage $\left(V_{o c}\right)$, short-circuit current density (Jsc) and highest power conversion efficiency (PCE) electrical parameters were summarized and listed in Table 1. Which could be ascribed to the decreases the recombination of electron-hole pairs and very increase contact surface with perovskite films.

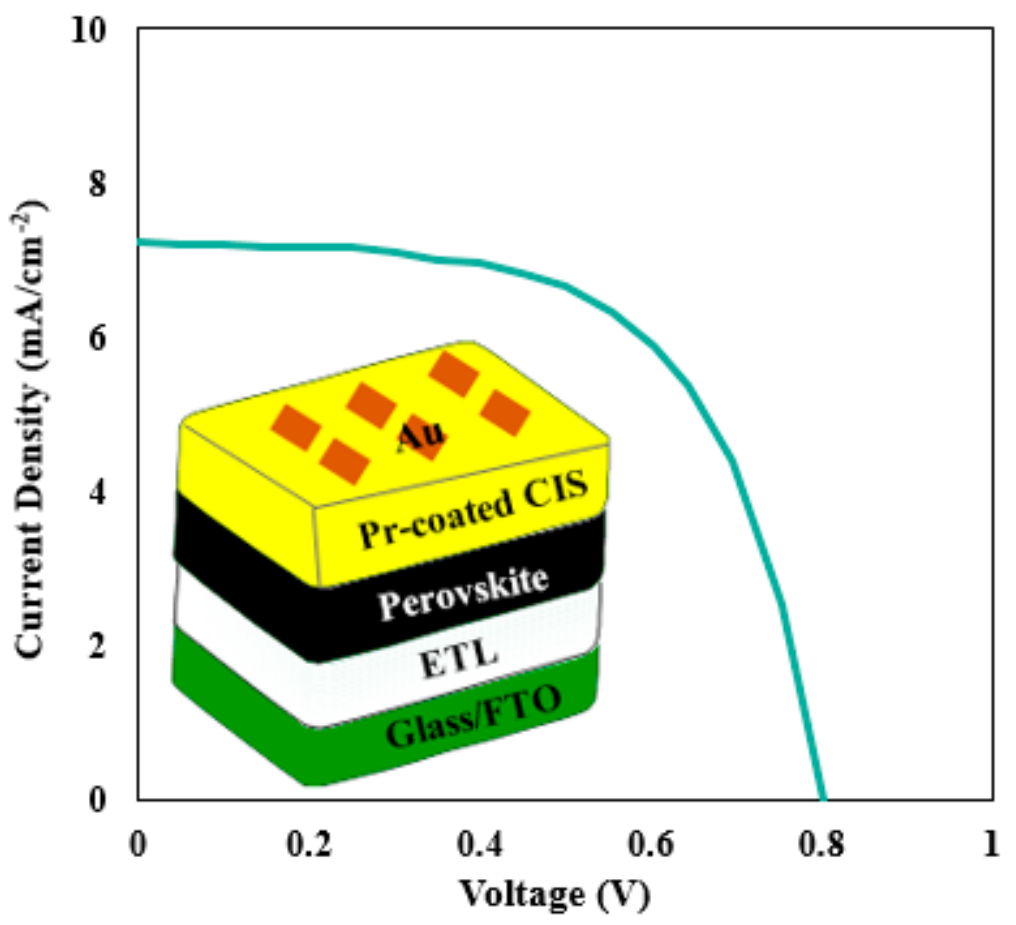

Figure 1. $J-V$ curves of organic-inorganic PSC based on Pr-doped CIS ETLs under AM 1.5 G, 100 $\mathrm{mW} / \mathrm{cm}^{2}$ illumination.

Table 1. Photovoltaic parameters of organic-inorganic PSC devices.

\begin{tabular}{ccccc}
\hline Electron Transporting Layers & $\mathrm{Jsc}\left(\mathbf{m A} / \mathbf{c m}^{2}\right)$ & Voc $(\mathbf{V})$ & FF (\%) & Efficiency (\%) \\
\hline $\mathrm{FTO} / \mathrm{TiO}_{2} /$ Perovskite/Pr-doped CIS/Au & 7.22 & 0.76 & 20.03 & 10.99 \\
\hline
\end{tabular}

\section{Conclusions}

In summary, in this study, we have suggested a new Pr-doped CIS as the THM layer and its photoelectric performance tested for organic-inorganic PSC by the J-V curve.

Funding: This work received no external funding.

Acknowledgments: The authors gratefully acknowledge the partial support from the Research Council of the Iran University of Science and Technology.

Conflicts of Interest: The authors declare no conflict of interest. 


\section{References}

1. Zhoua, H.; Yanga, L.; Guib, P.; Gricec, C.R.; Songa, Z.; Wang, H.; Fang, G., Ga-doped ZnO nanorod scaffold for high-performance, hole-transport-layer-free, self-powered $\mathrm{CH}_{3} \mathrm{NH}_{3} \mathrm{PbI}_{3}$ perovskite photodetectors. Sol. Energy Mater. Sol. Cells 2019, 193, 246.

2. Wu, W.Q.; Wang, Q.; Fang, Y.; Shao, Y.; Tang, S.; Deng, Y.; Lu, H.; Liu, Y.; Li, T.; Yang, Z.; Gruverman, A., Molecular doping enabled scalable blading of efficient hole-transport-layer-free perovskite solar cells. Nat. Commun. 2018, 9, 1625.

3. Ahn, S.M.; Jung, E.D.; Kim, S.H.; Kim, H.; Lee, S.; Song, M.H.; Kim J.Y. Nanomechanical Approach for Flexibility of Organic-Inorganic Hybrid Perovskite Solar Cells. Nano Lett. 2019, doi:10.1021/acs.nanolett.9b00796.

4. Kumar, V.B.; Gouda, L.; Porat, Z.; Gedanken, A., Sonochemical synthesis of CH3NH3PbI3 perovskite ultrafine nanocrystal sensitizers for solar energy applications. Ultrason. Sonochem. 2016, 32, 54-59.

5. Zhang, X.; Rui, Y.; Wang, Y.; Xua, J.; Wang, H.; Zhang, Q., Muller-Buschbaumc, P. SnO2 nanorod arrays with tailored area density as efficient electron transport layers for perovskite solar cells. J. Power Sources 2018, 402, 460-467.

6. Maleki, A.; Rahimi, J.; Valadi, K., Sulfonated Fe3O4@PVA superparamagnetic nanostructure: Design, in-situ preparation, characterization and application in the synthesis of imidazoles as a highly efficient organicinorganic Bronsted acid catalyst. Nano-Struct. Nano-Objects 2019, 18, 100264.

7. Lv, M.; Zhu, J.; Huang, Y.; Li, Y.; Shao, Z.; Xu, Y.; Dai, S., Colloidal CuInS2 Quantum Dots as Inorganic Hole-Transporting Material in Perovskite Solar Cells. ACS Appl. Mater. Interfaces 2015, 7, 17482-17488.

8. Maleki, A., $\mathrm{Fe}_{3} \mathrm{O}_{4} / \mathrm{SiO}_{2}$ nanoparticles: an efficient and magnetically recoverable nanocatalyst for the onepot multicomponent synthesis of diazepines. Tetrahedron 2012, 68, 7827-7833.

9. Maleki, A., One-pot multicomponent synthesis of diazepine derivatives using terminal alkynes in the presence of silica-supported superparamagnetic iron oxide nanoparticles. Tetrahedron Lett. 2013, 54, 20552059.

10. Maleki, A., One-pot three-component synthesis of pyrido [2', 1': 2, 3] imidazo [4, 5-c] isoquinolines using $\mathrm{Fe}_{3} \mathrm{O}_{4} @ \mathrm{SiO}_{2}-\mathrm{OSO}_{3} \mathrm{H}$ as an efficient heterogeneous nanocatalyst. RSC Adv. 2014, 4, 64169-64173.

11. Maleki, A., Synthesis of imidazo[1,2-a]pyridines using $\mathrm{Fe}_{3} \mathrm{O}_{4} @ \mathrm{SiO}_{2}$ as an efficient nanomagnetic catalyst via a one-pot multicomponent reaction. Helv. Chim. Acta 2014, 97, 587-593.

12. Maleki, A., Green oxidation protocol: Selective conversions of alcohols and alkenes to aldehydes, ketones and epoxides by using a new multiwall carbon nanotube-based hybrid nanocatalyst via ultrasound irradiation. Ultrason. Sonochem. 2018, 40, 460-464.

13. Maleki, A., An efficient magnetic heterogeneous nanocatalyst for the synthesis of pyrazinoporphyrazine macrocycles. Polycycl. Aromat. Compd. 2018, 38, 402-409.

14. Maleki, A.; Ghassemi, M.; Firouzi-Haji, R., Green multicomponent synthesis of four different classes of sixmembered $\mathrm{N}$-containing and $\mathrm{O}$-containing heterocycles catalyzed by an efficient chitosan-based magnetic bionanocomposite. Pure Appl. Chem. 2018, 90, 387-394.

15. Maleki, A.; Hajizadeh, Z.; Firouzi-Haji, R., Eco-friendly functionalization of magnetic halloysite nanotube with $\mathrm{SO}_{3} \mathrm{H}$ for synthesis of dihydropyrimidinones. Microporous Mesoporous Mater. 2018, 259, 46-53.

16. Maleki, A.; Hajizadeh, Z.; Abbasi, H., Surface modification of graphene oxide by citric acid and its application as a heterogeneous nanocatalyst in organic condensation reaction. Carbon Lett. 2018, 27, 42-49.

17. Maleki, A.; Ghalavand, R.; Firouzi-Haji, R., A novel and eco-friendly o-phenylendiamine stabilized on silica-coated magnetic nanocatalyst for the synthesis of indenoquinoline derivatives under ultrasonicassisted solvent-free conditions. Iran. J. Catal. 2018, 8, 221-229.

18. Maleki, A.; Akhlaghi, E.; Paydar, R., Design, synthesis, characterization and catalytic performance of a new cellulose-based magnetic nanocomposite in the one-pot three-component synthesis of $\alpha$-aminonitriles. Appl. Organometal. Chem. 2016, 30, 382-386.

19. Maleki, A.; Aghaei, M.; Ghamari, N., Facile synthesis of tetrahydrobenzoxanthenones via a one-pot threecomponent reaction using an eco-friendly and magnetized biopolymer chitosan-based heterogeneous nanocatalyst. Appl. Organometal. Chem. 2016, 30, 939-942.

20. Maleki, A.; Rahimi, R.; Maleki, S., Efficient oxidation and epoxidation using a chromium (VI)-based magnetic nanocomposite. Environ. Chem. Lett. 2016, 14, 195-199.

21. Maleki, A.; Movahed, H.; Ravaghi, P.; Kari, T., Facile in situ synthesis and characterization of a novel $\mathrm{PANI} / \mathrm{Fe}_{3} \mathrm{O}_{4} / \mathrm{Ag}$ nanocomposite and investigation of catalytic applications. RSC Adv. 2016, 6, 98777-98787. 
22. Maleki, A.; Aghaei, M.; Hafizi-Atabak, H.R.; Ferdowsi, M., Ultrasonic treatment of $\mathrm{CoFe}_{2} \mathrm{O}_{4} @ \mathrm{~B}_{2} \mathrm{O}_{3}-\mathrm{SiO}_{2}$ as a new hybrid magnetic composite nanostructure and catalytic application in the synthesis of dihydroquinazolinones. Ultrason. Sonochem. 2017, 37, 260-266.

23. Maleki, A.; Shaabani, A., Green and efficient synthesis of quinoxaline derivatives via ceric ammonium nitrate promoted and in situ aerobic oxidation of $\alpha$-hydroxy ketones and $\alpha$-keto oximes in aqueous media. Chem. Pharm. Bull. 2008, 56, 79-81.

24. Maleki, A.; Soleimani, E., One-pot three-component synthesis of 3-aminoimidazo[1,2-a] pyridines and pyrazines in the presence of silica sulfuric acid. Monatsh. Chem. 2007, 138, 73-76.

25. Maleki, A.; Behnam, M., Tandem oxidation process using ceric ammonium nitrate: Three-component synthesis of trisubstituted imidazoles under aerobic oxidation conditions. Synth. Commun. 2009, 39, 102-110.

(C) 2019 by the authors. Licensee MDPI, Basel, Switzerland. This article is an open access article distributed under the terms and conditions of the Creative Commons Attribution (CC BY) license (http://creativecommons.org/licenses/by/4.0/). 